\title{
The Fact/Value Dichotomy: Revisiting Putnam and Habermas
}

\author{
Sanjit Chakraborty ${ }^{1,2}$ (D)
}

Received: 30 August 2017 / Revised: 15 December 2017 / Accepted: 25 April 2018 /

Published online: 3 May 2018

(C) Springer Science+Business Media B.V., part of Springer Nature 2018

\begin{abstract}
Under the influence of Hilary Putnam's collapse of the fact/value dichotomy, a resurging approach that challenges the movements of American pragmatism and discourse ethics, I tease out in the first section of my paper the demand for the warranted assertibility hypothesis in Putnam's sense that may be possible, relying on moral realism to get rid of 'rampant Platonism'. Tracing back to 'communicative action' or the Habermasian way that puts forward the reciprocal understanding of discourse instigates the idea of life-world as composed of 'culturally transmitted and linguistically organized stock of interpretative patterns', this section looks for whether Habermas' psychoanalysis of prolonged discussion can accord with Putnam's thick ethical terms or not. The last section of the paper pitfalls Putnam's stance to accepting Habermas' 'discourse ethics' that centers around the context of entangling 'rational thoughts' to 'communication', but he introduces the idea of fallibilism in a rational query that also attacks the Habermasian metaphysical idea of the validity of ethical statements that goes towards the truth. My next attempt is to see whether Putnam's objective dictum towards morality that resonates the collapse of fact/value dichotomy from a universalistic stand can successfully evade Rorty's naive realism (structured by linguistic representation) and Habermas' 'sociologism about values' (a kind of minimalist ethics depending on solidarity) respectively. This sort of claim insists on a universalizable pattern of culture-relative value. I consider that the idea of a fact/value dichotomy engages with the inextricable entanglement between the normative and descriptive content, besides the epistemic values having exclusively intertwined with the structure of factual discourse that intends towards collapsing the fact/value dichotomy, a subjective universalizability predilection.
\end{abstract}

Sanjit Chakraborty

cogitosanjit@gmail.com

1 Department of Philosophy, Jadavpur University, Kolkata 700032, India

2 Department of Humanities and Social Sciences, National Institute of Technology, Durgapur, India 
Keywords Fact/value dichotomy · Warranted assertibility · Discourse ethics · Communicative action $\cdot$ Putnam $\cdot$ Habermas $\cdot$ Universalizability. Solidarity

The problem that worried me until now is apparently the 'Hobbesean way' to look on the dichotomy between moral values and legal values. The dichotomy problematizes the concept of valuation by supposing whether it may be made or discovered. We can consider in a rationalistic way that values are there in the third realm, and that the agents discover them consequently. The claim that an empiricist can raise against the humiliation of the armchair psychology of a priority (a view that offers that values are located in the third realm as independent of human knowledge), seems close to some 'factual assumptions'. Pragmatists consider, values are certainly 'fact centric' that is injected by the agents and is followed by others. So, the man made process of values has some experimentation mode that concerns about the good and bad of human life according to the situations, etc. This debate leads to another ongoing debate, the fact/value dichotomy, which is my main concern of the paper. The empiricists and pragmatists are on the same page regarding the thought that there is no dichotomy between facts and values. Rorty's study on his idol, John Dewey hints values as a 'factual knowledge', but Rorty does not hold up Dewey's 'objective realism' in his writing. The reason concentrates on the problem of the reference of the objective reality. Rorty strongly believes in the insufficient mode of the objective reality like William James, ${ }^{2}$ as no subject can stand the outside of their skin. Later rejecting the idea of objectivity by supporting 'solidarity', Rorty mainly draws his attention on the idea of the 'intrinsic nature' that differs from the notion of 'the thing in themselves' (Putnam 2002: 99). I think that a sort of metaphysical realism that Rorty resists can make a room for a subjective point of view. I firmly believe that it would be littered to reject the metaphysical interaction of the objectivity along with the idea that people may well have thoughts and beliefs that are associated with the objectivity or the external world. An agent's thoughts and beliefs are not in any sense mere intentional objects (intrinsic way) that are not related to the objectivity. The demand of subjective standards can be feasible only if we believe in the process of 'commonsense realism', otherwise subjective standard would be an abstract idea that discards any kind of reality. So my point is that we cannot deduct reality from our conceptual scheme.

Let me clarify first the sense organs that detect values from the facts, as if we can outlying red with blue through our sense organs (i.e. eyes). It seems that a person who has color perception acquires the ability to differentiate between two colors. Therefore, in a Kantian way, we can say that perception is a spontaneous exercise of concepts. If we agree with the empiricists, then we need to accept that values cannot

\footnotetext{
${ }^{1}$ Actually, for Hobbes, there is a very faint distinction we may draw between the moral and legal values, but it is true that the position that culminates a distinction between them is doubtlessly the idea of 'defenders', viz., the legal values have the propensity that can continue the defenders in the question of justice and injustice as ordered by the sovereign, whereas the defenders cannot continue his/her defence regarding the right or wrong of their perspective on moral values as it have no interrogate connection to the sovereign's proclamations. I assume that the legal values are more objective that have the stability stand, but moral values are more subjects centric, so it may be changeable according to the situation.

${ }^{2}$ William James thinks, 'In our cognitive as well as in our active life we are creative. We add, both to the subject and to the predicate part of reality. The world stands really mallable, waiting to receive its final touches at our hand... Man engenders truths upon it.' (James 1981: 115)
} 
be detected by the special sense organs, or in short, it cannot be perceptible, as perception is a method that is value neutral. Actually, perception deals with reason that has some factual base utilities. But values are concerned about wills, which have an intention or emotion base utility. It seems more interesting for me to relook at the pragmatist account that emphasizes perceptual experience is screaming with values or in a word perceptual experiences as value-laden. In the case of experiencing the taste of foods, here the value of good or bad is always associated with the taste of the objects (i.e. fact). The conception of objective value has some descriptive tendencies that facilitate the agent to criticise the process of valuation; valuation is a method that cannot be separable from our human activities. Believing in this idea leads a philosopher to foresee that human intelligence preserves moral human action. This conception of human intelligence that makes our communicative action more successful goes towards Habermas' Discourse Ethics that is the second important point I would like to analyse critically in this paper.

Before entering into the field of Discourse Ethics from Habermas' stance, I would like to make clear Hilary Putnam's standpoint on the warranted assertibility hypothesis. Putnam believes:

The correct formulation of "internal realism" is: truth is idealized warranted acceptability (i.e conformability by our sense data under epistemically ideal conditions). If language users had not existed, then conditions would not have been epistemically ideal, but that does not mean the above counterfactual (about the dinosaurs) would have been true; the counterfactual would have had a true instead of a false antecedent, but it would still be false. ${ }^{3}$

Putnam clarifies the conception of the warranted assertibiity is principally concerned about the objective truth in ethics. So, if we negotiate objectivity of ethics, then the warranted assertibility does not play any significant role. The contribution of warranted assertibility in the sense of early Putnam (Putnam as internal realist) attempts to connect truth under the ideal condition that sounds good enough. It is true that there are some cases where truth transcends the warranted assertibility under some ideal conditions in the sense of verifications like the 'statements about the cosmological universe' or 'the impossibility to determine truth' in the case of Brain in a vat'. Putnam cautions about some exceptions and says:

But in the same way, I argue, there is no reason to suppose that one cannot be what is called a "moral realist" in meta-ethics, that is, holds that some "value judgements" are true as a matter of objective fact, without holding that moral facts are or can be recognition transcendent facts. If something is a good solution to a problematical human situation, then part of the very notion of its being a good solution is that human beings can recognize that it is. We need not entertain the idea that something could be a good solution, although human beings are in principle unable to recognize that it is. That sort of rampant Platonism is incoherent. (Putnam 2002: 108-109)

\footnotetext{
${ }^{3}$ I am personally thankful to my mentor Hilary Putnam for this valuable comment.
} 
The mentioned quote indicates Putnam's indisposition to admit the 'rampant Platonism,' as he is reluctant to put the absoluteness of moral truth in the third realm that is beyond of any subjective/objective justification. Putnam seems to have an interest in seeing language as a game or use that was once propounded by Wittgenstein. Here inventing some new concepts and construing the general use of the concepts in society and science, one has to admit that moral truths are not situated out of the world, as the concepts are, in Putnam's words, always subject to criticism. So, following Dewey, a suggestive note can be drawn is that there may be some judgements where something is valuable without being the experience of the kind of valuing. The reason is that it undermines the principle of fallibilism, a controversial issue that inspires the way to insinuate a distinction between the warranted and unwarranted value judgements without putting them into the domain of transcendent truth.

Austin's model of truth emerges from the fact of the world where truth does not sound as a property rather an 'immanent truth' i.e. truth is a part of total corpus related to the reference of the words. Putnam considers that a term refers to an object only if there is a causal linkage (without any accidental or magical reference) that encompass between the object and the particular word. Putnam hinges a problem of traditional realism to ensure that the world cannot be a fixed totality of objects (the realist's myth of readymade world) given independently of the human mind. He intends to devoid any correspondence relation between truth and the state of affairs from a mind independent level. Truth for him is the warranted assetibility of the sentence rather than correspondence between the sentence and a fact. It looks interesting when he replies to Blackburn, 'It is we who divide up 'the world'- that is, the events, state of affairs, and physical, social etc., systems that we talk about- into 'objects', 'properties', and 'relation', and we do this in variety of ways. 'Object', 'entity', 'property', (and 'relation') have not one fixed use but an ever-expanding open family of uses. Because 'exist' and 'entity' are conceptually linked, the same is true of 'exist'.' (Putnam 1995: 243).

\section{What Does Communicative Action Say?}

Habermas in The Theory of Communicative Action (1981) puts forward his notable idea of communicative action by distinguishing it from the strategic and instrumental action. While strategic action relates to the social world, instrumental action relates mainly to the non-social world. However, communicative action focuses on how reciprocal understanding among two persons (or more) is possible in a social world. Brian Douglas quotes from Habermas,

The concept of communicative action refers to the interaction of at least two subjects capable of speech and action who establish interpersonal relations (whether by verbals or by extra-verbal means). The actors seek to reach an understanding about the action situation and their plans of action in order to coordinate their actions by way of agreement. The central concept of interpretation refers in the first instance to negotiating definitions of the situations which admit of consensus... Language is given a prominent place in this model. (Douglas 2009) 
The primordial question is here how does this communicative action go on? And the answer we find out in Habermas' work is that it can be possible by the 'performative mode of action,' where an individual understands the norms and reasons of a claim made by the other partner in a communicating act. The other partner might also provide the series of reasons in order to challenge the claim made by the first partner, with an aim to make the whole of discourse free from the domination of power and subjugation. Hence, what counts in a free discourse is reasoning. In such a procedure, both the partners engage themselves in communicative action by providing better argumentations on properly structured reasoned grounds. Discourse begins when one partner starts challenging the validity claims of the other partner through some rational argumentations. The process of discourse has some conditions that need to be fulfilled. All the participants who are involved here express their consultation while attaining any decision and the participants in turn, must be serious presenting arguments on the rational grounds. This leads to avoidance of manipulations and violence of any kind in a healthy systematic and integrated society.

One of the significant aspects that must be taken into consideration in dealing with Habermas' communicative action is that the communication among the participants takes place only in a 'lifeworld', in which we are located. Three components are crucial in a 'lifeworld' - society, culture and personality. The 'lifeworld' is reproduced through communicative action and it changes over time. A system is not reproduced through communicative action and reason. The systems are governed initially by market, power and money, and there is significantly no space for mutual understanding. Habermas does not completely withdraw the significance of the systems, because he never says that without any system, it is possible for a society to assimilate itself and run smoothly. However, what he asserts is frequently called 'lifeworld', which opens up the prospect of intersubjective communication from domination, power and subjugation. Habermas says that in a 'lifeworld', through communicative action, culture is reproduced, society is integrated, and personality is socialized. In Habermas' words:

Under the functional aspect of mutual understanding, communicative action serves to transmit and renew cultural knowledge; under the aspect of coordinating action, it serves social integration and the establishment of solidarity; finally, under the aspect of socialization, communicative action serves the formation of personal identities... Corresponding to these processes of cultural reproduction, social integration and socialization are the structural components of the life world: culture, society, person. (Habermas 1987: 137)

In a society, 'lifeworld' enables us to view things from a subjective standpoint; on the other hand, the systems perspective takes everything from an objective standpoint. 'Lifeworld' refers to the inescapable reality of a person that encounters while being encircled in a number of social phenomena. Habermas thinks that 'lifeworld' is composed of 'culturally transmitted and linguistically organized stock of interpretative patterns', 'lifeworld' finds its expression in texts, and various culturally constructed artefacts, and through cultural groups. It sounds true that Habermas undertakes his task of framing the communicative action as a move from particularity to universality, but at the same time, he is equally sensitive to the impossibilities faced by individuals in stepping beyond the societal frame world in which they are situated or beyond the 
'lifeworld' situation, which entangles them. Communicative action takes the assist of dialogue and integrates them, shapes them in the way, so that certain human constraints relating to language (being biased in thoughts, particularism etc.) can be overtaken; and in its place, a shared understanding can prosper. Habermas says, 'this process of communication has a strong potential to "prevent citizens from acting as isolated monads on the basis of their own self interests" (Habermas 1987: 52). Habermas' project is a step to realize a common identity among all men overruling all regional/ national boundaries, and promoting shared beliefs, mutual trust, love, faith etc.

\section{Putnam on Habermas' 'Discourse Ethics'}

In modern philosophy, Immanuel Kant fairly introduces the idea of objectivity in his epistemology by bringing the conception of the universal as a necessary condition, which constitutes all the objects in relation to its syntactic power. One alternative that Putnam focuses on his writing talks about a pragmatic alternative of the objective judgement, a stance of 'intersubjective' point of view that derives from a historical background by considering the ethical ideals of rightness and wrongness in terms of the speakers and the hearers' communications. So, the Kantian ideas of objectivity, in the sense of the universal, descend in the procedure of conversation chiefly based on the dialogical communication with others. Objectivity turns here as an ethical quality of the communicating.

In the startling work The Theory of Communicative Action, Vol 2 (1987), Habermas, in defence of his magnificent prolegma 'discourse ethics', has taken two revolutionary stances. The first one is obviously the distinction between values and norms. In addition, the second one is, unquestionably, the idea of "communicative action". The norm, a sort of valid statement of obligation, which is associated to universality, rests on the discourse ethics concerning the rational thought and communicative action together; whereas values are regarded as the social products that have a naturalistic outlook and vary with different 'lifeworlds'. However, while it is true that Habermas' way of considering norms treats the Kantian idea of norms in a different angle, we may treat, in tune with Kant's ethics, the Habermasian norm that is allied to the communicative actions, as both of them believe that we need to treat others not as a means, but as an end. Now, I would like to relook at the Habermasian term 'communicative action' that is actually bestowed on the communicative procedures in an ideal rational discourse by bringing the idea of the norm of sincerity etc. that are discarded from manipulation. It seems difficult to claim that the universal norms are more fitted with the communicative action. Putnam argues:

It cannot be the case that the only universally valid norm refers solely to Discourse. It is, after all, possible for anyone to recognize truth-telling as a binding norm, while otherwise, being guided solely by "enlightened egotism"..., after all, communicative action is contrasted with manipulation, and as such a person can manipulate people without violating the maxims of "sincerity, truth-telling, and saying only what one believes to be rationally warranted.” (Putnam 2002: 114-115) 
One can resist that in such a case as if an agent would like to kill another; here it need not violate any maxim that is interrelated to the 'discourse ethics'. But Putnam rejects this unfair criticism to remind that Habermas had a positive belief in Kant's categorical imperative. He solely accepts the maxim that one should treat others as an end and not as a means. Habermas also thinks that people have disagreements about values and norms, and the disagreement about the ethical value is obviously a significant fact of life that searches for a middle way. Therefore, Habermas abhors considering any final ethical systems or rules of conduct. Putnam calls Habermas as a 'minimalist Kantian moral philosopher' who sets a 'final court of appeal' that depends on 'ideal speech situation' by discarding it from the mere rules as to how to conduct in the case of disagreements.

\section{Putnam-Habermas}

Christine Korsgaard, an eminent Kantian tries to refute the dichotomy between norms and values portrayed by Habermas. In her splendid book, The Sources of Normativity (1996), she intends to set up that values are not in any way the object on which we incline. Even it is not something like 'initial psychological impulses' that is governed in the case of valuation. For Korsgaard, the processes are maintained by an adaptation of maxims that inspire us to afford value, and not to value this. Korsgaard considers, 'I argue for the conclusion that human beings must see ourselves as value-conferring and must therefore value humanity as an end in itself.' (Korsgaard 1998: 60-61).

The problem that Putnam finds in Korsgaard's thought is the universalizing pattern of maxims and laws that are imposed upon the subject by containing value terms as contrasted to thick ethical terms like kind, cruel etc. The thick ethical terms are associated with the 'ethical maxims' hardly can transit it into the 'universal laws', as the extensions of the thick ethical terms are, according to Putnam, universally unintelligible.

Putnam argues against Habermas' discourse ethics by introducing an example. Let us think that there is a thick ethical word like 'chastity' in X's (subject) "social world", but it may be lacking in Y's (others) "social world". If X follows a norm that "Avoid unchaste behavior", then this norm makes no sense to Y as in their "social world" there is no relevant extension of the thick ethical terms. One can discuss and continue their discussion regarding some norms or concepts only if both have some minimal account of knowledge about the concepts and others that are related to the concepts. Putnam thinks:

The problem this poses for discourse ethics is that discussion (as opposed to negotiation) presupposes that the question at issue is cognitively meaningful. If we suppose it is not, as Ramsey remarked, such a "discussion" "consists in A saying he would feel guilty if he weren't constant, B saying he wouldn't feel guilty in the least". (Putnam 2002: 121)

Until the discussion can find out some good reason, it would lead to continuing conversions where it would be tricky to conceive a common vocabulary or common 
understanding from a normative sense of communication. It sounds true that if Habermas does not accept Apel's jargon of "transcendental pragmatics"4 as Putnam claimed, then the charge of continued discussion without negotiation can be fruitful, and in this case, Habermas, like Apel, brought two interconnected ideas - 'all those affected', i.e. 'the widest possible community' and 'the truth that settled upon the indefinitely continued discussion'. This is a way one can drop the idea of thick ethical terms. Still, the crucial dilemma that may arise, as Putnam claimed, is that to snub thick ethical terms in the way mentioned will undermine the application of truth as it is defined in Apel's jargon and also accepted by Habermas (early Habermas before the writing of The Theory of Communicative Action, Vol 1, 1981). In this case, the both mentioned sides (see Putnam's example) of the place of truth would be blocked like in the first side; and it would be problematic to determine which action can be regarded as chaste or which one is unchaste, as there is no valid judgment regarding the thick ethical terms that have been accepted by the communicators ( $\mathrm{X}$ and $\mathrm{Y}$ as mentioned above). Besides, if the attempts of one of the communicators are to universalize the maxim 'Avoid unchaste behavior', then all the participants have to agree about those truths in an ideal discussion. Therefore, it would be interesting to initiate the concept of truth by converging continued discussion under ideal conditions.

One more problem can be noticed in the conception of truth that was once portrayed by Karl-Otto-Apel (1998). Apel's truth theory (i.e. a minimalist account) concerns about the agreement in the limit of indefinitely continued discussion that is based on communicative action in the sense of normativity. This continuous discussion procedure (where the verification of truths and valid judgments in ideal conditions (ideal consensus depends on ultimate opinion) are not beyond human capabilities as they omit negotiation for accepting social agreement) is close to anti-realism where truth relates to human verification. Even Putnam has also changed his mind regarding his early belief that "truth can be identified with "idealized rational acceptability"' (Putnam 2002: 124). In our physical science and common sense, there are a lot of unverifiable facts or judgments that do not depend on human verification or empirical understanding. Even this may be the same for ethical judgments too. Apel aims to see the use of the performative contradiction argument as the 'ultimate' base of his discourse ethics and believes that the denying process of any rule (in discourse ethics) leads to selfcontradiction (Apel 1987: 280-281). Performative contradiction in discourse ethics for Apel is a kind of guide that helps to identify the nominal rules of discourse ethics. A well-known maxim that has been celebrated by the ethicists for a long-time is that "agents' duties must be knowable by the agents. If they are not, then there is no need to consider it as agents' duties". If we analyze this maxim in the context of the ideal conditions of a prolonged discussion as Apel and Habermas claimed, then some problems will arise as follows.

Putnam thinks that the definition of ideal discussion is governed in the way that the concerning the norms and maxim of 'discourse ethics' would be accepted (not

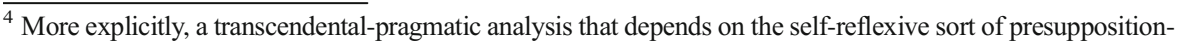
analysis chiefly exposes that in the practice of argumentation in communicative action, the certain normative proprieties play a pertinent role in which anybody who would like the process of all competent participants to perform as rational evaluators ought to wish for every competent participant to identify as ideally regulating through their discursive commitments. Here reasons are assessed by the reasonable assessors depending on the universalistic rational ethos. (Please see, Apel 1991: 261-78)
} 
manipulated) by all participants in an ideal condition. Here, the question is 'what constitutes the justification' and 'how it may be possible if we accept the truth or valid judgments as an outcome of the indefinitely prolonged discussion'. Apel answers this question by introducing the transcendental justification that intertwines rationality and pursues the truth. However, it is true that this intertwine procedure is considered as a presupposed matter of ethical rationality. Even the idea of prolonged discussion of the ethical queries sounds incorrect. There are some judgments, where a large number of people cannot get any resolution of their arguments.

Putnam takes the case of an example, where a father's act is considered as cruel, because he teases his child and denies that the child's tears are actually serious. The father straightforwardly claims that the child 'has to learn to take it.' Any of two things might happen with the father. First, he might be an obtuse/simple minded personality who is innocently trying to make his child learn to take the tears, or, he might be a sadist, who enjoys the pain of others. In this case, the father by engaging himself in an act of psychological cruelty teases the child, and enjoys the child's tears. Here, the question arises, whether the whole community will come to an agreement that the father's act constitutes cruelty. There may arise a situation where a majority of the people even shares the same obtuseness the father (might have) shared. It might happen that people are not genuinely always bad, and they love rational arguments; accordingly, they go on for endless discussions, where the participants involved do not resort to manipulations, listen to each other, and help others for better arguments. This is absolutely a genuine act without being aware of what discourse means. The father in the example (and of course, most of the other people) might not even understand this process or the implications of such a discourse. This speech situation might also turn out well as an 'ideal' though the members participating in the discussion are unaware of the requirements of an 'ideal speech situation' that there must be a consensus, a rational consensus after all.

Putnam's claim is that the discussants in the above example are not wrong in disobeying the norms of discourse ethics, but are wrong in stating the thick ethical terms that are particular to certain ethical problems. For Putnam, the problem arises in using the thick ethical terms such as 'obtuse', 'trace of sadism' and so on. Here, Putnam goes in tune with Habermas in saying that an ideal discussion is (many a times) equivalent to the ideal of psychoanalysis, especially, when Putnam uses the scientific sounding expression 'a trace of sadism'. It seems to me that, considering the example, it is difficult to determine and find out any solid agreement (by means of discourse) whether the father is actually obtuse or a sadist. Therefore, Putnam says that using these kinds of terms is dangerous. Hence, Putnam accepts Habermas' psychoanalysis in case of using these kinds of terms such as 'obtuse', 'sadist' etc.

A particular ambiguity that Putnam finds in Habermas 'discourse ethics' is mentioned here. Putnam thinks that it would be more ambiguous to consider 'discourse ethics' as having an independent standing on its own, and not dependent as part of the broader perspective of ethics. Putnam argues:

If Habermas will, as I am trying to persuade him to do, restrict the claims of discourse ethics; if specifically, he will say that discourse ethics is a part of ethics, a valuable and important part to be sure, but not one that can stand on its own, not the foundation (or the foundation in "modernity") of all the "validity" 
that ethics can possess, then, I believe, he will be on very much the right track. But if one attempts to defend the more ambitious claims that he and Apel have made on behalf of discourse ethics, then either there will be no reason to believe the claims (this will be the case if "discourse ethics" is restricted to some definite set of norms that are supposed to characterize reason) or the claims will be empty. For if the claim that the correct verdict in an ethical dispute will be arrived at in an ideal speech situation just means that it will be arrived at if the disputants are ideally morally sensitive, imaginative, impartial, and so on, then the claim is a purely "grammatical" one; it provides no content to the notion of a "correct verdict in an ethical dispute" that that notion did not independently possess... (Putnam 2002: 128-129)

There is another challenge, which can be posed against Habermas. One can ask Habermas whether we can exclude the persons who are quite irrational or those who are not eager to engage themselves in a rational discourse from the 'all affected persons,' a group of persons who would like to discuss and express their arguments not by manipulation, but to find out an agreement in favour of rational thoughts. A big contradiction is noticed here.

\section{Critiquing the Fact/Value Dichotomy}

The reason for which Putnam is eager to accept Habermas' 'discourse ethics' initially centers around the context of entangling 'rational thoughts' to 'communication' that Habermas proposed. Putnam does not like to accept Habermas' thought, as, for him, a 'valid ethical judgement' is not able to bind all rational beings in a framework and compels them to accept it by all persons in a prolonged discussion that is carried out by the norms of the discourse ethics. The metaphysical idea of 'discourse ethics' is what Putnam challenged in his writing by arguing against the 'validity of the ethical judgements.' Putnam agrees with Habermas especially on the conception of informed discussion in respect of discourse ethics etc., but he challenges the conception of necessarily rightness or wrongness of the value concepts. The conclusion or the decision of the affected person does not seem always right. Putnam believes that in any rational inquiry, fallibilism takes a significant role in its methodology. The process of knowledge does not depend always on revision. It seems true that we develop different descriptions or new concepts and all these processes are related to language game that goes towards new truth or it would be better to say expand language. Therefore, a fruitful discussion always removes any sort of hierarchy or rigidity. Therefore, Putnam attacks Habermas' conception of rightness that is derived from the continued discussion celebrated by all affected agents in an ideal condition (without manipulating each other) in order to achieve a conception of necessary rightness that will be followed by all in a society. However, I will be happy to clarify here that Putnam firmly accepts Habermas' aspect of rational inquiry of discourse ethics. What Putnam attack is especially Habermas' metaphysical idea of the validity of an ethical statement that goes towards the truth. Putnam challenges Habermas' idea of universal agreement, a Kantian view. By calling it a utopia, Putnam thinks that it hardly follows that a continuous long discussion inspires every person to an agreement. Therefore, there will 
be a lack of consensus in the case of deriving truth and justification. Habermas' conception of consent to all can be considered as an unrealistic framework that cannot fit with the democratic politics. In one way, we can justify Habermas' claims regarding universal agreement or the consent of all in his Theory of Communicative Action by considering the ideal speech situation as a practice that one should follow. Habermas does not hold that the rules of communication and the formal conducts that are related to rules and present in communication help us to achieve the final truth.

Putnam mainly attacks Habermas' idea of designing the fact/value dichotomy. Putnam considers that this dichotomy is hostile to any fruitful inquiry. Putnam calls this dichotomy a discussion stopper in the case of exercising rational thought in a discourse. I think that this debate began with the query of whether moral judgements or moral conceptions are subjective or objective. As Habermas and Rorty believe in the subjective standpoints of value judgements, so it is easy for them to accept the dichotomy, while Putnam rejects any ontological explanation in favour of objectivity of ethics or subjective explanation that deals with it. He actually believes in the process of objectivity of ethics that convince him to collapse the dichotomy of fact and value.

Rorty, as a prominent pragmatist, does not find any sense in the claim of metaphysical realism that looks at objectivity as 'things-in-themselves'. Accepting solidarity leads Rorty to accept also the view that the agent's words are unable to represent things outside the agent's skin. Putnam finds a kind of self-reputation on Rorty's claim. Putnam does not think that culture can determine what is true and false wholly. He calls Rorty's position a naive realism that hints about sociological facts and the norms of our culture wholly determines what is true and false. Kilanowski writes:

Putnam further points out that the Rortian notion of solidarity requires exactly what he is talking about: "common sense realism about the objective existence of the people one is in 'solidarity' with." Because of that, we should not confuse a metaphysical notion of objectivity (that we can make sense of talk about things "as they are in themselves") with the "ordinary idea that our thoughts and beliefs refer to things in the world"... Is it that "we should not" because there are things in the world to which we refer, or is it that we have to assume that they exist and that this assumption is a requirement of our common sense realism? It seems that for Putnam, the latter is correct. (Putnam 2015: 833)

The confusing matter that worries Kilanowski and I is obviously Putnam's claim in favour of linguistic representation of something that is located outside language. By this argument, Putnam challenges Rorty's position of linguistic representation within language by vindicating the notion of the idea of common sense. If we look at Habermas now, then we will notice that for him, values are naturalistically represented. Habermas thinks that values are contingent social products that can be changed in regard to different life-worlds. Putnam sees the problem in Habermas' conception of sociology of value. Putnam says:

It is precisely by appreciating the necessity of discourse ethics that we can appreciate how fatal it is to Habermas' own philosophical-political project to make any concessions to what we might call "sociologism about values" - to treat value disputes as, in effect, mere social conflicts to be resolved (although they are 
frequently that too) and not as rational disagreements calling for a decision as to where the better reasons lie. (Putnam 2002: 121)

Putnam urges that Habermas' account goes towards minimalist ethics by possessing a kind of relative validity of values in a social world. Certain thick ethical terms like cruelty, kindness, etc. are no doubt relative to some particular community. They possess denotation, which has some formal universality. However, the problem is that the content that involves denotation is not related to the universal. Putnam's position is that values in no way can discard norms unaffectedly. So, Habermas' universal laws in favor of ethical maxim would be challenged. Putnam thinks,

For if our ethical maxims contain thick ethical concepts - as they obviously do then making them into "universal laws" will be problematic in any view according to which what the extensions of those ethical concepts are is a question that has no universally intelligible answer. (Putnam 2002: 120)

Putnam's denial of the fact/value dichotomy eventually articulates a solid human concern or a concern about the world/objectivity where values cannot be considered as mere expressions of agent's emotions but as a package of the real world. The collapse of fact/value enhancement is a celebrated plea that underlines humanistic vision of flourishing human reasoning with some significant content that tends toward the world of facts. The exact description of the epistemic values intends us "closer to truth about the world". Putnam's conception on 'ethics with content' fortify the claims that we can get a thick ethical concept only when we locate a liaison between the concept and the ethical point of view that is associated with the use of the concept. To understand the procedure we have to see language as a whole (language as a social art), not as an innate faculty. Ethics in a deeper sense is related to moral language that infuses the fact/value entanglement. The factual description and valuation cannot be conceived in segregation from each other as any description effectively engages valuation.

Putnam argues that if we accept Habermas and Rorty's conception of solidarity and subjectivity regarding any maxims (like 'don't be cruel') that, according to them, is associated with social products and differs from community to community, then the maxim cannot achieve any universal valid agreement. In searching for better judgements or valid arguments in discourse ethics, Habermas has to maintain that the arguments need to be present and approved by the social world where fallibility of knowledge does not get any value as the discussion tries to defend the correct answer with a better judgement of the agent (i.e. rational discussants). Putnam thinks that the purpose would be fulfilled if Habermas accepts objectivity in his discourse ethics. He firmly believes that objectivity has allied to universal values that represent some commonsensical notion. It would be interesting to argue that the thick ethical terms that Putnam mentioned have some denotation in a particular community. Similarly, this reason has a formal universal stance. Habermas may agree with the discussion by saying that in his discourse ethics, he focuses on the rules of communication and is not interested about mere rules that intends towards correct answers. Two Habermasian ways to see "words" as having a relative denotation that interconnects with the particular community have some roots in a particular language in our social world. I think that this process cannot pursue any hostility regarding the agreement of a 
continuing discussion of the rational agent. Putnam argues against Habermas, especially, on the conception of the formal rules that, for him, cannot mingle with the correct verdict. He argues that if we consider a situation where the disputants have the quality of impartial ideally morally sensible etc. (even if they agree to the correct verdict) then the whole process according to Putnam becomes a grammatical one. Commenting on Putnam's stance Kilanowski rightly emphasises:

As Putnam claims Kantian ethics, as well as discourse ethics are empty formalism - they are empty and formal unless we supply them with content from Levinasian and Aristotelian thought, and concerns with democracy, toleration or pluralism. In other words, the notion of an "ideal speech situation" is, for Putnam, empty due to the absence of thick ethical concepts. (Kilanowski 2015: 837)

One point needs to be clarified here is that, in Habermas' ethical discourse, the content of ethical discussion, along with the formal rules of conduct, is no doubt value centric. And the communication procedure has some shared paradigm, as it is common to all agents. So, Habermasian process accepts values that are ethically aligned. The basic problem of Habermas' thesis, according to Putnam, is how it would be possible to gather different parties and involve them to continue a discussion towards an agreement without manipulating each other. If we admit that a large number of people in a community follow some formal conducts for moving towards an agreement depending on the communicative action procedures, then the other group of people in the same community can challenge the content of the formal conduct or rules. Habermas may reply that in discourse ethics, an articulation have no place. However, that does not show that this marginalized people are out of society, and that they are not affected by the agreement that comes from the continuous discussion of the rational agents. However, Habermas clarifies that the rational discussants do not have any attitude to manipulate the other, as the main norm in communicative action is to defend moral values by recognizing the other people as an end, and in no means, one can treat the other as a means. Following the Kantian principle, Habermas introduces an additional value in his discourse ethics that is often called the value of a human being.

\section{Way Out}

Let me revisit Putnam's magnificent stand as to why he introduces the thick ethical terms in his ethics. The chief ambition of Putnam is to collapse the dichotomy between fact and values. As he considers that this dichotomy offers a subjective preference, Putnam considers that we always impose the norms and laws on us to provide it a universal stand by entangling with moral values or we can say in particular the thick ethical terms like sensitive, kind, cruel, etc., He firmly believes that the vocabulary of norms would be meaningless if there is no human manifold of values. In Ethics without Ontology, Putnam writes, '... ethics and mathematics can and do possess objectivity without being about sublime or intangible objects such as 'Platonic forms' or 'abstract entities"... (Putnam 2004: 2).

Putnam discards any kind of priority based moral values. His position is close to moral realism that tries to neglect any kind of final set of moral truths that is construed 
by rigid morality, although Putnam suggests that the latter Habermas changes his mind and believes in the idea that some values are objective. Kilanowski clarifies:

Habermas admitted in reply to Putnam's comments, as Putnam mentions that the objective validity of Kantian "norms" presupposes the objective applicability of the value terms that this norm contain. But the problem is that Habermas considers only some values as subjective - universalizable values. There are others that he considers merely subjective to individual or group projects - they are non universalizable values, which are not prohibited by a valid "norm". (Kilanowski 2015: 839)

Though it sounds from Putnam's writing that Putnam rebuffs any sort of principle of universalizability as he does not think that there may be some point where everyone will agree, his approach to capabilities theory can accept the universalizability principle. But it is true that there are no justified grounds to prove this argument. The fondness of objectivity inspired him to see common sense realism, and in this process, he offers a warranted assertibility hypothesis that tries to judge the right/wrong and truth/falsity of the statements. To determine truth is no doubt one of the biggest challenges of the philosophical theories. Even in ethics, one may be concerned about the truth-value of ethical judgements. Putnam considers that one can be a good moral realist in determining the value judgement by discarding transcendent facts to ensure the role of objective facts that hold moral values. Putnam writes that we need no better ground for treating 'value judgements as capable of truth and falsity than the fact that we can and do treat them as capable of warranted assertability and warranted deniability'. (Putnam 2002: 110).

To find out a superior resolution, Putnam does not believe a single criterion that could judge the warranted assertability in any ethical judgement. Like Wittgenstein, Putnam has also a fascination to think that a judgement could turn out right only if the community bestows their agreement with it. For Putnam, truth is not only a shared paradigm of our community that is culturally relative and determined by the warranted assertability. Truth is actually the objective fact that is related to reality. To flourish this argument, he takes different concerns together with his ethical approach like the Aristotelian concern, the talks about human ability, and Kantian aspects of the good life and treatment of human beings as an end, even he was close to Habermas and Rorty regarding the maxim of responsible use of human freedom.

The most elegant point that needs attention here is obviously whether Putnam rightly believes in Rorty's jargon, according to which, an agent could not stand outside of her/ his thoughts and concepts as reality resides in it. In Word and Life, as an externalist, Putnam presents his opinion against Rorty by saying:

In starting [the argument of Rorty's that I just criticized], I said that it is impossible to stand outside and compare our thought and language, on the one hand, with the world on the other; and, indeed this is the way in which Rorty puts matters. But if we agree that it is unintelligible to say, 'We sometimes succeed in comparing language and thought with reality as it is in itself', then we should realize that it is also unintelligible to say, 'It is impossible to stand outside and compare our thought and language with the world'... (Putnam 1994: 299) 
These lines perfectly point out that Putnam had no belief in Rorty's argument in favour of the subjective representation of morality cum reality. The very impressive point that Putnam raised against Rorty and Habermas who believe in the subjective representation of morality is that the non-commonsensical view on our language may present a direct contact with reality (as much as possible) seems like a rambling argument. The facility only comes when we formulate it in a procedure of piecemeal that touches with the distinct constituents of reality. Putnam worries about the thought that to accept the piecemeal process regarding the relation between words and the world has a propensity to represent that kicking the object absorbs the particular object; but in the case of description, it cannot involve the particular object at all. Now, the question is why Putnam alters his opinion against subjectivity and takes a stand in favour of objectivity. He does not believe in commonsensical representation of the objective values. The reason in Putnam's own words:

In fact, I have never claimed that the objectivity or universality of values (objectivity and universality are not the same thing, by the way!), or of truths about any other subject matter, "rests on" the notion of representation. believe that many, many different sorts of statements are objectively true; am I supposed to believe that all of these different sorts of truth "rest on" the semantical claim that there is a relation of representation (more, precisely, of reference, or, to use Tarski's term for the converse of the reference relation, a relation of "satisfaction") between terms and particular entities, ordered pairs of entities, ordered triples of entities, and so on. (Putnam 2015: 853)

We find a quite similar opinion in Akeel Bilgrami's writing who believes that fact contains value in a mind-independent sense. Bilgrami in his well-known paper 'The Visibility of Value?' (2016) mainly disenchanted the philosophical outlook of value from any metanormative sense. According to the sentimentalist (David Hume and Adam Smith) views, values are human disposition that has a causal link to the world. The extension of this trend quests for mind-dependence value, a thesis that brings about the conception of psychological reliance value being not related to the objective sense. Bilgrami argues:

One can have both these perspectives (engaged and detached) on oneself, but not at the same time. In other words, one cannot at the same time both intend and predict that one will do something. The one perspective crowds the other perspective out. Moreover, and more importantly, unless one had an engaged perspective on oneself, one would not be a practical agent. (Bilgrami 2016: 925)

This approach shows that intention crowded out prediction. One cannot intend and predict the same thing to do at a same time. If you think that you will intend to do a particular thing, then in the same time, you cannot predict that someone will do it for you. The point that Bilgrami appreciates is an intention that directly brings about the action. Similarly, the desire of an agent represents what is the enviable object in the world. Bilgrami holds that if one recognizes agency in terms amiable to the minddependence of value, then the question of agency will become extraneous. Here we can mislay the explanandum. Mind-dependence cannot portrait what is called agency. 
Mind-independence values commence with the sense of objective world that is a fundamental criterion of objectivity. It seems to me pertinent that the content of one's thought is metaphysically distinct from the referent of the thought. The conception of action tends towards objectivity, not to the psychological states of mind. Actions basically intend to value (in an objective sense), not to the method of valuing (it sounds more psychological). The consensus of mind-dependence value is a paradox. Bilgrami writes:

Desires in us are nothing if there are no desirabilities (and undesirabilities) or values (and disvalues) in the world as well. And our agency consists in the fact that these desirabilities or values in the world make normative demands on us that trigger our desires upon which we act, as (practical) agents. And the challenge that views desires as self-standing simply denies this, claiming instead that agency consists merely in acting on our desires and those desires do not answer to any external calling of desirabilities or values in the world. (Bilgrami 2016: 929)

Habermas, in his article, 'Reconciliation through the Public use of Reason: Remarks on John Rawls,' (1995) makes a very comprehensible and lucid distinction between norms and values. The essential features of norms are that they are normative in nature. Norms cope with what one ought to do. A norm is said to be either valid or invalid in Habermasian sense, especially because here the validity claim is determined on the basis of how rationally it has been formed in a universal discourse. Since norms are formed out of a universal discourse, they are absolutely universal and unconditional, according to Habermas. On the other hand, values guide us as to what conduct is desirable and what is not. Values carry an evaluative meaning. It is because values involve a preference/choice of a particular thing/good/action, because the desirability of a particular value may vary from one culture to another, from one group to another.

If we remember Habermas' hypothesis, then we will see that, in determining the truth-value of moral judgements, objectivity plays no role. Here, the important thing is that in a continued discussion, a particular community's rational members would like to determine their value that satisfies the norms of 'discourse ethics'. Habermas claims:

Norms inform decisions as to what one ought to do, values inform decisions as to what conduct is desirable. . Norms raise a binary validity claim in virtue of which they are said to be either valid or invalid. . Values, by contrast, fix relations of preference that signify that certain goods are more attractive than others; hence, we can assent to evaluative statements to a greater or lesser degree. The obligatory force of norms has the absolute meaning of an unconditional and universal duty. . . The attractiveness of values reflects on evaluation and a transitive ordering of goods that has become established in particular cultures or has been adopted by particular groups. (Habermas 1995: 114-115)

In The Collapse of Fact/Value Dichotomy, the promising question that Putnam deciphers is nothing but the inextricable entanglement between the normative and 
descriptive content; especially, in the case of value terms like the cruel or psychological cruelty, etc. Putnam thinks that a father who teased his baby to cry by claiming that 'He has to learn to take it', can be considered in Habermas' sense as a psychological cruelty, which as a judgement has value. Now what the father did ('psychological cruelty') with his child cannot be regarded as 'cruelty' only if, in his particular culture, it becomes permissible. In this case, for the general people like us, it would look like an ethnocentric model. Most of the cultures dislike and does not permit to 'use cruel method to children', but Putnam finds a problem in the method of 'using cruelty' to the children that differ from one culture to another. We will be unable to find out any objective content if we articulate the 'universal value' of the judgment like 'Don't use cruel methods to children'. The second interesting criticism that Putnam raised against Habermas is that if Habermas accepts the 'psychological cruelty' of the father to his child as a sort of value judgment that can be objectively right, then the value judgement will not achieve any 'universal norm' standard. It obviously would be a nonuniversaliazable value whose validity and acceptance precisely depend on the particular culture. So, here, the dilemma that retrieves the objection that Putnam argued mainly concerns about the procedure of intending to resolve the extension of each value term not only depending on the "universalizable" values possessing, but also upon the conception of culture-relative "validity". Putnam himself clarifies, "I also said that the idea that the non-universalizable values possess only culture-relative validity is unacceptable ethically.' (Putnam 2015: 859).

This is one of the standard claims that insist on a universalizable pattern of culture-relative value and I agree with Putnam that an expression of fact/value dichotomy involves as a normative stance, besides the epistemic values having inseparably entangled with the formation of factual discourse that intends towards collapsing the fact/value dichotomy, a subjective universalizability predilection.

\section{References}

Apel, K. O. (1987). The problem of philosophical foundation in light of a transcendental pragmatics of language. In K. Baynes, J. Bohman, \& T. McCarthy (Eds.), After philosophy. Cambridge: MIT Press.

Apel, K. O. (1991). 'A planetary macroethics for mankind: The need, the apparent difficulty, and the eventual possibility'. In E. Deutsch (Ed.), Culture and modernity: East-west philosophic perspectives (pp. 261278). Honolulu: University of Hawaii Press.

Apel, K. O. (1998). Towards a transformation of philosophy. (trans. G. Adey \& D. Fisby). Milwaukee: Marquette University Press.

Bilgrami, A. (2016). The visibility of value. Social Research, 83(4), 919-945.

Douglas, B. (2009). Communicative action: A way forward for inter-religious dialogue. The Journal of Interreligious Dialogue, 49. www.irdialogue.org.

Habermas, J. (1981). The Theory of Communicative Action. Reason and the rationalization of society. Vol. One. (trans. T. McCarthy). Boston: Beacon Press.

Habermas, J. (1987). The Theory of Communicative Action: 'Lifeworld' and system: A critique of functionalist reason. Vol. Two. (trans. T. McCarthy). Boston: Beacon Press.

Habermas, J. (1995). Reconciliation through the public use of reason: Remarks on John Rawls' Political Liberalism. Journal of Philosophy, 92 (3), 109-131.

James, W. (1981). Pragmatism. (ed. B. Kuklick). Indianapolis: Hackett Publishing. 
Kilanwoski, M. (2015). 'Toward a responsible and rational ethical discussion: A critique of Putnam Pragmatic Approach'. In R. E. Auxier, D. R. Anderson \& L. E. Hahn (Eds.), The philosophy of Hilary Putnam. Chicago: Open Court.

Korsgaard, C. (1996). The sources of normativity. Cambridge: Cambridge University Press.

Korsgaard, C. (1998). Motivation, metaphysics and the value of the self: A reply to Ginsborg, Guyer, and Schneewind. Ethics, 109(1), 49-66.

Putnam, H. (1994). Words and life, J. Conant (ed.), Cambridge: Harvard University Press.

Putnam, H. (1995). 'Replies to Simon Blackburn'. In P. Clark \& B. Hale (Eds.), Reading Putnam. London: Blackwell Oxford.

Putnam, H. (2002). The collapse of the fact/value dichotomy and other essays. Cambridge: Harvard University Press.

Putnam, H. (2004). Ethics without ontology. Cambridge: Harvard University Press.

Putnam, H. (2015). The philosophy of Hilary Putnam. R. E. Auxier, D. R. Anderson \& L. E. Hahn (Eds.). Chicago: Open Court. 